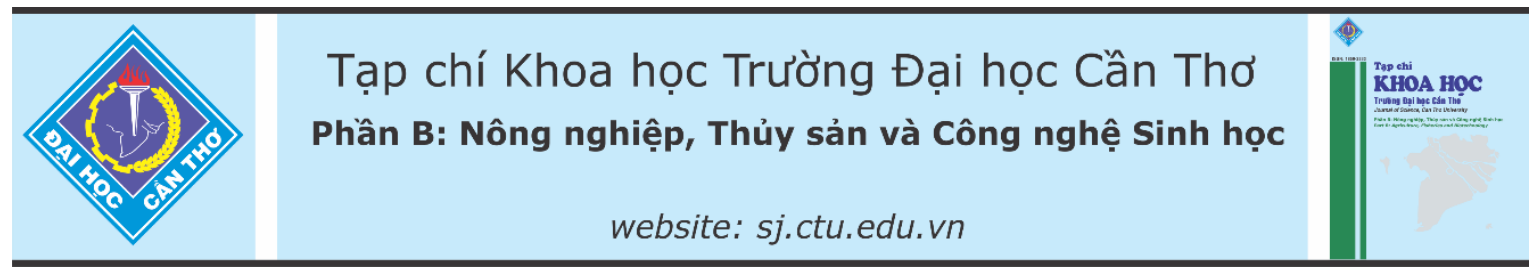

DOI:10.22144/ctu.jvn.2021.104

\title{
HIỆN TRANG KHAI THÁC VÀ NGUỒN LỢI ỐC CÀ NA (Tomlinia frausseni Thach, 2014) KHU VỤ̉C BIỂN VEN BỜ TỈNH TRÀ VINH
}

\author{
Trần Văn Tiến ${ }^{1,2^{*}}$, Ngô Thị Thu Thảo ${ }^{3}$, Lê Thị Cẩm Hà ${ }^{1,2}$ và Nguyễn Văn Tú ${ }^{1,2}$ \\ ${ }^{l}$ Viện Sinh hoc nhiệt đới, Viện Hàn lâm Khoa hoc và Công nghệ Việt Nam \\ ${ }^{2}$ Hoc viện Khoa họ và Công nghệ, Viện Hàn lâm Khoa học và Công nghệ Việt Nam \\ ${ }^{3}$ Khoa Thủy sản, Truờng Đai hoc Cần Tho \\ *Người chịu trách nhiệm về bài viết:Trần Văn Tiến (email: tvtien.itb@gmail.com)
}

\section{Thông tin chung:}

Ngày nhận bài: $18 / 11 / 2020$

Ngày nhận bài sủa: 26/12/2020

Ngày duyệt đăng: 25/06/2021

Title:

The quo-status of fisheries and resources of Tomlinia

frausseni Thach, 2014 in Tra Vinh estuary

\section{Tù khóa:}

Khả năng khai thác, ốc Cà na, Tomlinia frausseni, Trà Vinh, vùng ven $b o^{\prime}$

\section{Keywords:}

Ca na snail, estuary, exploitation, Tomlinia frausseni, Tra Vinh province

\section{ABSTRACT}

Tomlinia frausseni Thach, 2014 - Ca na snail, an edible marine snail, mainly distributes on the coast of the Mekong Delta. Forty-two fishermen living in Tra Vinh coastal area were interviewed to evaluate the current status of fisheries of the species from March to May 2018. Semi-structured questionnaires chiefly focusing on technical and financial aspects, advantages, and disadvantages were used to collect data. The resources of $T$. frausseni was estimated using Catch-Effort methods between may $12^{\text {th }}$ and September 19 ${ }^{\text {th }}$, 2019. The results showed that originally, the gastropod fishing started in 2011, and annually, the exploiting season took place from March to October of the lunar calendar in the coastal zone. Longline cage traps were used to catch the snail with an average vessel capacity of $31.36 \pm 2.23 \mathrm{CV}$ and tonnage of $2.85 \pm 0.13$ tons/vessel. The annual fishing yield was 6.432,74 $\pm 207,98$ $\mathrm{kg} /$ year. With $1.33 \pm 0.03$ million VND/trip to invest in a fishing trip, fishermen got return 1,87 $\pm 0,10$ million VND/trip, and the equity rate of benefit was $0,40 \pm 0,07$ million VND/trip. The population size of Tomlinia frausseni was estimated to be $73,904 \pm 6,684 \mathrm{~kg}(95 \% \mathrm{CI}: 59,802,88,006 \mathrm{~kg})$ with a catchability of $9.894 * 10^{-4}$ $\left(95 \%\right.$ CI: $\left.6.218 * 10^{-4}, 13.570^{*} 10^{-4}\right)$. Results of the investigation are baseline data for further research in biology and ecology of the gastropod in the Travinh coastal area.

\section{TÓM TĂT}

Tomlinia frausseni Thach, 2014 - ốc Cà na, loài có giá trị làm thực phẩm, phân bố chủ yếu ở khu vực vùng ven biển Đồng bằng sông Cửu Long. Nghiên cúu hiện trạng khai thác ốc Cà na khu vực biển ven bờ tỉnh Trà Vinh được thực hiện tù̀ tháng 3 đến tháng 8 năm 2018 thông qua phỏng vấn trực tiếp 42 ngu dân về khía cạnh kỹ thuạt, khía cạn tài chính và nhũng khó khăn, thuận lợi. Nguồn lợi ốc Cà na được ước tính dựa trên phưong pháp Sản lương-Cuò̀ng lực khai thác (Catch-Effort methods) trong khoảng thời gian tù̀ 12 tháng 5 đến 19 tháng 9 năm 2019. Kết quả cho thấy nghề khai thác ốc bắt đầu tù năm 2011, mùa vu khai thác tù tháng 3 đến tháng 10 âm lịch, và khu vục khai thác chính tại vùng biển ven bờ. Phưong thức khai thác chủ yếu là sử dụng bẫy lồng với công suất tàu trung bình $31,36 \pm 2,23$ CV và trọng tải trung bình 2,85 \pm 0,13 tấn/tàu. Sản lượng khai thác trung bình năm đạt 6.432,74 $\pm 207,98$ kg. Tổng chi phí trung bình cho một chuyến đi biển 1,33 $\pm 0,03$ triệu đồng và tổng doanh thu 1,87 $\pm 0,10$ triệu đồng. Tỉ suất lợi nhuận của nghề là $0,40 \pm 0,07$ triệu đồng cho một chuyến biển. Nguồn lợi ốc Cà na vùng biển ven bờ tỉnh Trà Vinh là $73.904 \pm 6.684 \mathrm{~kg}(95 \% \mathrm{CI}: 59.802,88.006 \mathrm{~kg})$ với hệ số hiệu quả đánh bắt 9,894*10-

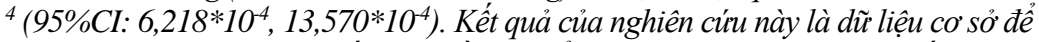
thục hiện các nghiên cứu tiếp theo về đặc điểm sinh học và sinh thái của ốc Cà na tại khu vục vùng biển ven bò̀ tỉnh Trà Vinh. 


\section{GIỚI THIẸU}

Động vật thân mềm biển là một trong những nguồn cung cấp protein thiết yếu trong khẩu phần ăn của con người bên cạnh cá, giáp xác. Theo báo cáo của Food and Agriculture Organization of the United Nations (FAO, 2018), sản lượng khai thác và nuôi trồng động vật thân mềm trên thế giới luôn tăng trong giai đoạn 1990-2016. Việt Nam là một trong những quốc gia đi đầu trong khai thác và nuôi trồng động vật thân mềm biển (FAO, 2018). Đến thời điểm hiện tại, có hơn 1.300 loài ốc biển được ghi nhận trên khu vực vùng biển Việt Nam (Bùi Quang Nghị, 2011; Hylleberg \& Kilburn, 2003; Thach, 2014, 2016a, 2016b, 2017). Trong số đó, nhiều loài có giá trị kinh tế hiện đang được người dân khai thác và nuôi, trồng ở vùng biển Việt Nam. Các loài ốc biển này đóng vai trò rất quan trọng trong phát triển kinh tế và xã hội của cộng đồng dân cư ven biển Việt
Nam (Chinh, 1999; Đặng Ngọc Thanh, 2003; Nguyễn Quang Hùng và ctv., 2016).

Loài Tomlinia frausseni Thach, 2014 - có tên tiếng Việt là ốc Cà na, ốc Cau, ốc Xanh, hay ốc Nho, loài này chỉ mới được ghi nhận là loài phân bố đặc hữu trên khu vực Đông Nam Bộ và vùng Đồng bằng sông Cửu Long (ĐBSCL) (Hình 1). Chúng phân bố ở độ sâu từ $1-10 \mathrm{~m}$ trên nền đáy bùn tại khu vực rừng ngập mặn, cửa sông và vùng triều (Đỗ Văn Tứ và ctv., 2019; Global Biodiversity Information Facility [GBIF], 2020; Molluscabase, 2020; Thach, 2014). Bởi đây là loài có giá trị kinh tế về giá trị làm thực phẩm cũng như mới xuất hiện gần đây với sinh khối lớn trên vùng biển của Việt Nam nên được người dân khai thác mà chưa được quản lý và kiểm soát. Đến thời điểm hiện tại, chưa có các nghiên cứu về hiện trạng khai thác và nguồn lợi ốc Cà na tại các khu vực vùng triều của Việt Nam để có các giải pháp quản lý và sử dụng hợp lý nguồn lợi này.

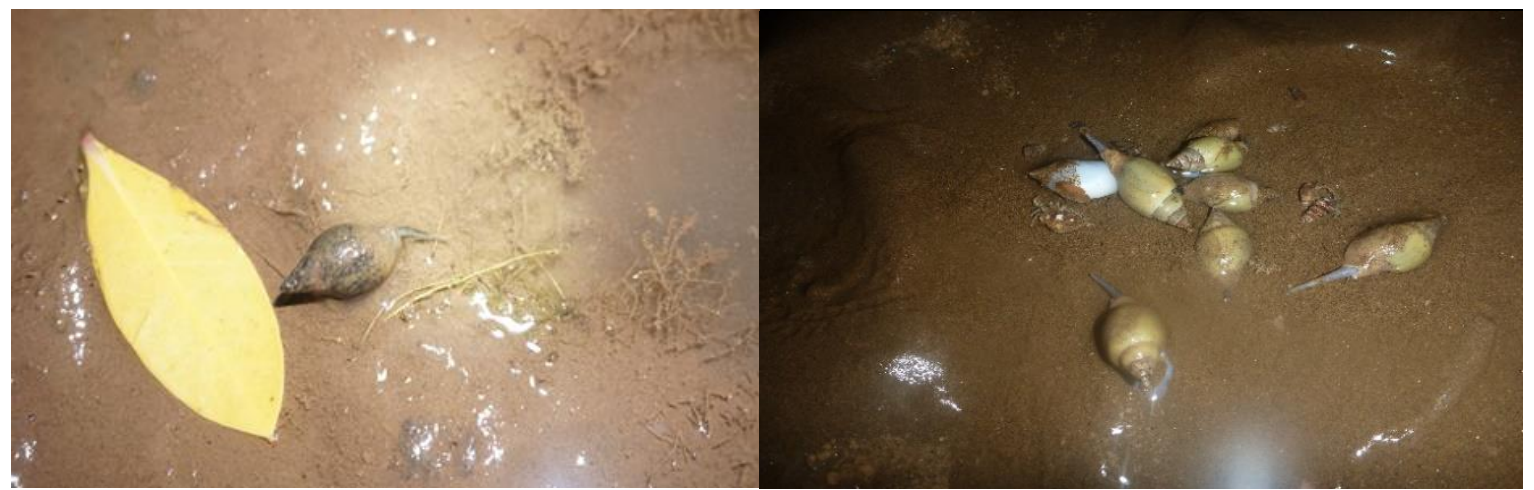

Hình 1. Hình ảnh ốc Cà na ngoài tự nhiên

Nghiên cứu này được thực hiện góp phần cung cấp các tư liệu về hiện trạng khai thác và nguồn lợi ốc Cà na khu vực vùng biển ven bờ tỉnh Trà Vinh. Kết quả của nghiên cứu là cơ sở cho các nghiên cứu về sinh học và sinh thái cũng như đề xuất các biện pháp quản lý khai thác ốc Cà na vùng biển ven bờ tỉnh Trà Vinh nói riêng và Việt Nam nói chung nhằm sử dụng và khai thác hợp lý nguồn tài nguyên này một cách bền vững trong tương lai.

\section{PHƯƠNG PHÁP NGHIÊN CÚU}

\subsection{Hiện trạng khai thác nguồn lợi ốc Cà na}

Nghiên cứu đánh giá hiện trạng khai thác ốc Cà na được thực hiện từ tháng 3 đến tháng 8 năm 2018 thông qua phỏng vấn trực tiếp 42 ngư dân khai thác ốc Cà na tại khu vực ven biển tỉnh Trà Vinh sử dụng bảng câu hỏi đã được soạn sẵn. Nội dung phỏng vấn chủ yếu bao gồm khía cạnh kỹ thuật như mùa vụ, ngư trường, phương tiện khai thác, ngư cụ, lực lượng lao động, thời gian khai thác và sản lượng; khía cạnh tài chính gồm có chi phí cố định, chi phí biến đổi, doanh thu, lợi nhuận và tỷ suất lợi nhuận; và những khó khăn cũng như thuận lợi của nghề khai thác ốc Cà na. Các thông số tính toán cho hiệu quả tài chính bao gồm tổng chi phí, tổng thu nhập, lợi nhuận, và tỷ suất lợi nhuận theo (Nguyễn Thanh Long, 2015, 2016, 2017; Nguyễn Thanh Long và ctv., 2018; Long et al., 2018). Cụ thể:

- Tổng thu nhập = tổng số tiền bán sản phẩm

- Tổng chi phí = Tổng chi phí biến đổi + Tổng chi phí cố định (Chi phí khấu hao)

- Lợi nhuận = Tổng thu nhập - Tổng chi phí

- Tỉ suất lợi nhuận = Tổng lợi nhuận/Tổng chi phí

Dữ liệu thu thập thông qua bảng phỏng vấn được mã hóa và tiến hành phân tích các theo phương pháp thống kê mô tả và trình bày dưới dạng các giá trị Trung bình \pm Sai số chuẩn (Mean $\pm \mathrm{SE}$ ), giá trị nhỏ 
nhất - lớn nhất (Min-Max), tỷ lệ (\%) hoặc tần xuất xuất hiện $(\%)$ sử dụng phần mềm Rstudio version 1.2.5052 với gói "psych".

\subsection{Nguồn lợi ốc Cà na phân bố ở khu vực vùng ven biển Trà Vinh}

Khu vực nghiên cứu hay ngư trường khai thác ốc là vùng biển ven bờ tỉnh Trà Vinh theo Quyết định số: 12/2013/QĐ-UBND ngày 09/05/2013 của Ủy ban nhân dân tỉnh Trà Vinh (UBND tỉnh Trà Vinh, 2013). Số liệu về sản lượng ốc khai thác hàng ngày được được ghi nhận từ 39 ngư dân khai thác bằng hình thức bẫy lồng xếp tại khu vực biển ven bờ tỉnh Trà Vinh trong khoảng thời gian từ 12 tháng 5 đến 19 tháng 9 năm 2019. Cường lực khai thác được tính là số lần đi biển khai thác ốc của tàu/ngày. Số liệu về sản lượng ốc Cà na đánh bắt được và cường lực khai thác được tổng hợp theo theo tuần. Tổng cộng có 19 tuần khai thác liên tục được ghi nhận trong thời gian nghiên cứu.

Sử dụng phương pháp tính sản lượng - cường lực khai thác (Catch-Effort methods) theo Fischler (1965), Krebs (1999) và Leslie and Davis (1939) để đánh giá nguồn lợi ốc Cà na ở khu vực vùng ven biển Trà Vinh với các giả thiết: i) quần thể ốc Cà na vùng biển ven bờ Trà Vinh là quần thể đóng (không có sự di cư và nhập cư); ii) xác suất bắt được mỗi cá thể ốc không thay đổi trong suốt thời gian đánh bắt; và iii) xác suất bắt được mỗi cá thể ốc Cà na trong các bẫy lồng xếp là như nhau.

Khả năng khai thác và kích thước quần thể ốc Cà na được tính toán theo mô hình của Leslie and Davis (1939) và Krebs (1999) theo công thức (1) và (2). Nếu hệ số khả năng khai thác/đánh bắt "C" nhỏ hơn 0,02 tức là $2 \%$ kích thước của quần thể bị đánh bắt thì kích thước của quần thể được tính toán sử dụng mô hình của DeLury (1947) bằng cách lấy logarit tự nhiên 2 vế công thức (2) được công thức (3) (DeLury, 1947; Krebs, 1999). Các phân tích được thực hiện sử dụng phần mềm Rstudio version 1.2.5052 với gói phần mềm "FSA" (Derek, 2016) và trình bày biểu đồ với gói phần mềm "ggplot2".

Khả năng khai thác (Catchability):

$$
C=\frac{-\sum_{i=1}^{S} Y i(K i-\bar{K})}{\sum_{i=1}^{S}(K i-\bar{K})^{2}}
$$

Kích thước quần thể: $\quad \widehat{N}=\bar{K}+\frac{\bar{Y}}{C}$

Trong đó: Yi là sản lượng khai thác/ngư cụ hay năng suất khai thác $=\frac{c i}{f i}$

ci là sản lượng khai thác $(\mathrm{kg})$. fi là cường lực khai thác (lần/ngày).

$\bar{K}$ là giá trị trung bình của $\mathrm{Ki}$ (sản lượng khai thác tích lũy $)=\left(\sum K i / s\right)$

$\mathrm{s}$ là tổng số lượng mẫu $(\mathrm{i}=1,2,3 \ldots \mathrm{s})$

$$
\log \left(\frac{c i}{f i}\right)=\log (C \widehat{N})-C \bar{K}
$$

\section{KẾT QUẢ VÀ THẢO LUẬN}

\subsection{Hiện trạng khai thác nguồn lợi ốc Cà na}

\subsubsection{Khía canh kỹ thuật}

Thời điểm xuất hiện ban đầu, mùa vu, và đặc điểm khu vục khai thác

Kết quả khảo sát ghi nhận ốc Cà na được người dân khai thác bắt đầu từ năm 2011 với phương thức chủ yếu bằng ghe cào. Đến năm 2013, khi các phương pháp sản xuất lồng bẫy phát triển và UBND tỉnh Trà Vinh (2013) ban hành theo Quyết định số: 12/2013/QĐ-UBND cấm hình thức khai thác bằng ghe cào tại khu vực biển ven bờ thì hình thức khai thác bằng bẫy lồng bắt đầu phát triển. Thực tế cho thấy nghề khai thác ốc Cà na không phải là nghề truyền thống của ngư dân khu vực này. Trước kia, người dân chủ yếu khai thác các loài hải sản khác như cá, giáp xác, nghêu, sò huyết (Nguyễn Thanh Long, 2017; Oanh et al., 2018; Trương Sĩ Kỳ và ctv., 1996; UBND tỉnh Trà Vinh, 2013). Nghề khai thác ốc Cà na bằng bẫy lồng xếp chỉ mới bắt đầu khi loài ốc này xuất hiện với sinh khối lớn và chúng trở lên có giá trị thương mại. Có thể nhận định, khai thác ốc Cà na là nghề còn non trẻ trong các nghề khai thác thủy sản tự nhiên của người dân vùng biển ven bờ tỉnh Trà Vinh.

Hoạt động khai thác ốc Cà na sử dụng bẫy lồng xếp của người dân khu vực biển ven bờ triều tỉnh Trà Vinh mang tính mùa vụ. Trong số 42 ngư dân khai thác có $71,43 \%$ người dân cho rằng mùa vụ khai thác bắt đầu vào tháng 3 (âm lịch), 19,05\% người khai thác vào tháng 4 , và số còn lại vào tháng 5. Thời gian kết thúc khai thác vào tháng 9 chiếm $54,76 \%$, tháng 10 chiếm $30,95 \%$ và số còn lại vào tháng 8 và tháng 11 âm lịch. Như vậy, mùa vụ khai thác ốc vào tháng 3 và kết thúc vào tháng 9 và 10 âm lịch. Mùa vụ khai thác ốc Cà na tại khu vực biển ven bờ tỉnh Trà Vinh giống với mùa vụ khai thác các đối tượng thủy sản khác tại vùng ĐBSCL. Việc khai thác ốc theo mùa vụ này phù hợp với điều kiện thời tiết và điều kiện tự nhiên ở tỉnh Trà Vinh (Nguyễn Thanh Long, 2017; Nguyễn Thanh Long và ctv., 2018; Oanh et al., 2018; UBND tỉnh Trà Vinh, 2013). 
Người dân khai thác ốc chủ yếu hoạt động trên khu vực biển ven bờ với khoảng cách so với bờ trung bình khoảng $6,07 \pm 0,34 \mathrm{~km}$. Đặc điểm nền đáy nơi khai thác được ngư dân cho rằng chủ yếu là nền bùn - sét với khoảng 73,57 $\pm 1,53 \%$ và cát khoảng 26,43 $\pm 1,53 \%$. Kết quả khảo sát cho thấy người dân khai thác ốc Cà na chủ yếu thuộc vùng biển ven bờ tại khu vực vùng triều tỉnh Trà Vinh, nơi có độ sâu từ 1 - 10 m (Hoàng Văn Huân, 2018; UBND tỉnh Trà Vinh, 2013).

\section{Phuơng tiện và đặc điểm ngu cu nghề khai thác óc Càna}

Kết quả khảo sát ghi nhận nghề khai thác ốc Cà na sử dụng tàu khai thác có trọng tải trung bình 2,85 $\pm 0,13$ tấn với trọng tải nhỏ nhất 1,5 tấn và lớn nhất là 4,2 tấn. Công suất trung bình của tàu khai thác là $31,36 \pm 2,23 \mathrm{CV}$ trong đó, công suất nhỏ nhất $6 \mathrm{CV}$ và lớn nhất $60 \mathrm{CV}$ (Bảng 1$)$. Trọng tải và công suất của tàu khai thác ốc Cà na tại khu vực biển ven bờ Trà Vinh thấp hơn so với các tàu thuộc ngành nghề khai thác thủy sản khác bao gồm lưới rê, lưới kéo, lưới đáy, rập xếp tại khu vực vùng ĐBSCL (Long et al., 2018; Nguyễn Thanh Long và ctv., 2018). Trọng tải và công suất tàu khai thác ốc Cà na thích hợp cho việc khai thác tại khu vực biển ven bờ (UBND tỉnh Trà Vinh, 2013).
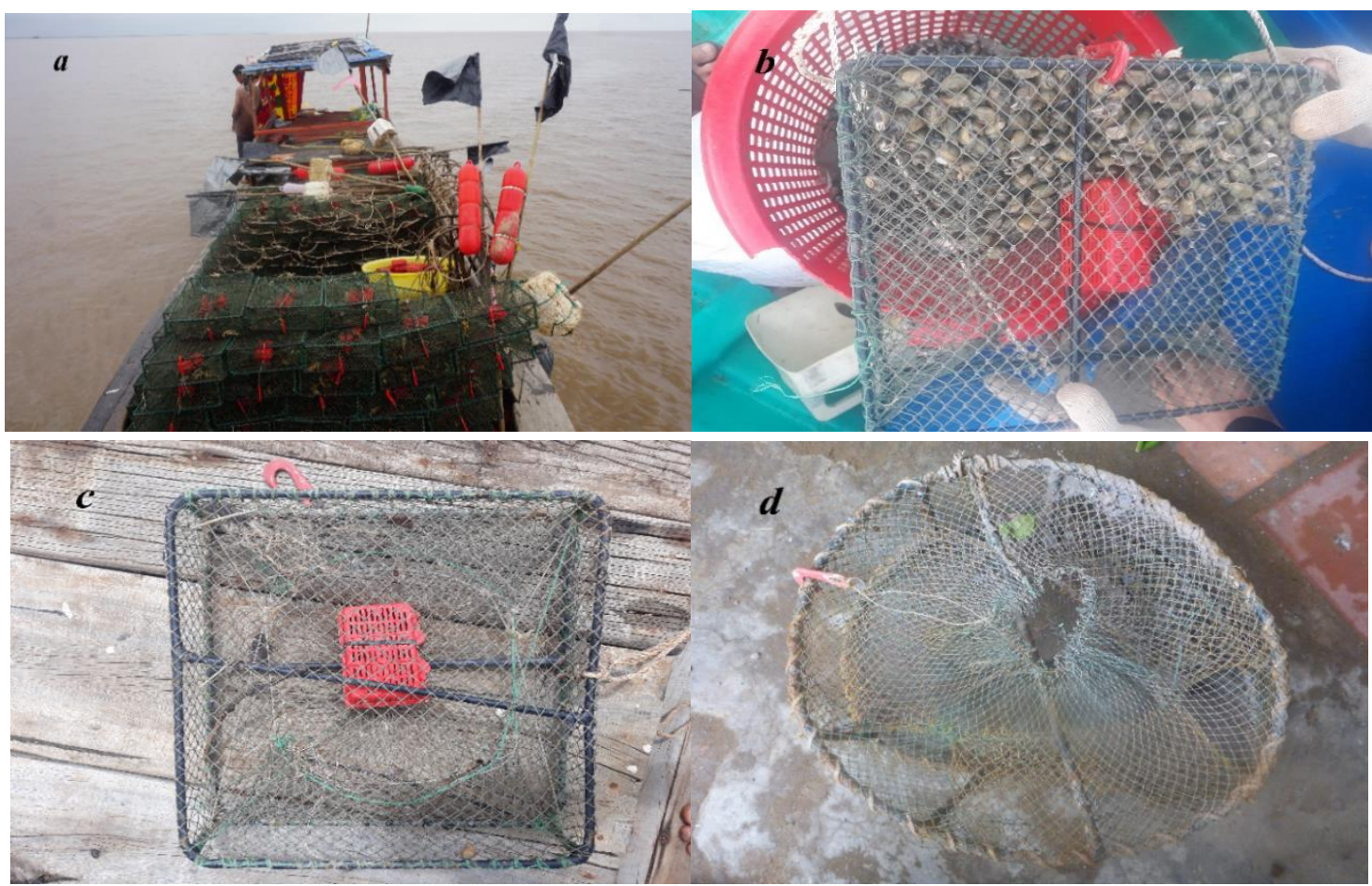

Hình 2. Phương tiện và ngư cụ khai thác ốc Cà na

$a$ - Tàu khai thác và bẫy lồng xếp; $b$ - Lồng bẫy sau thời gian đặt; c-Lồng bẫy hình hộp chũ nhật; $d$ - Lồng bẫy hình tru tròn 
Số thuyền viên tham gia khai thác ốc trung bình $2,21 \pm 0,08$ người. Trong đó, số lao động của gia đình tham gia khai thác có $1,86 \pm 0,05$ người chiếm $86,90 \pm 2,98 \%$ tổng số lao động trên tàu. Số lao động thuê mướn trung bình $1,07 \pm 0,07$ người chiếm $13,10 \pm 2,98 \%$ số thuyền viên. Kết quả khảo sát cho thấy, ngư dân tham gia nghề khai thác ốc chủ yếu sử dụng lao động trong gia đình để giảm chi phí thuê mướn đồng thời nâng cao thu nhập của gia đình
(Bảng 2). So sánh với các ngành nghề khai thác khác tại vùng ĐBSCL cho thấy nghề khai thác ốc Cà na có số lượng thuyền viên thấp hơn so với các ngành nghề khai thác khác. Điều này phù hợp với công suất và trọng tải của tàu khai thác tại khu vực vùng biển ven bờ (Long et al., 2018; Nguyễn Thanh Long, 2018). Nhìn chung, hoạt động khai thác ốc Cà na góp phần cung cấp công ăn việc làm cho hoạt động sinh kế của ngư dân.

Bảng 2. Lực lượng lao động tham gia khai thác ốc Cà na tại vùng biển ven bờ tỉnh Trà Vinh (Cõ̃ mẫu $=42$ )

\begin{tabular}{lrr}
\hline Nội dung & TB \pm SE (Min - Max) & Tỷ lệ (\%) \\
\hline Số lao động gia đình (người) & $1,86 \pm 0,05(1,00-2,00)$ & $86,90 \pm 2,98$ \\
Số lao động thuê (người) & $1,07 \pm 0,07(1,00-2,00)$ & $13,10 \pm 2,98$ \\
Tồng sồ thuyền viên (người) & $2,21 \pm 0,08(1,00-4,00)$ & 100 \\
\hline
\end{tabular}

Thời gian thả bẫy hay ngâm bẫy bắt ốc trong 1 chuyến đi biển trung bình $9,68 \pm 0,26$ giờ. Thời gian cho 1 chuyến đi thu hoạch - thu bẫy và đặt bẫy lại trung bình $6,26 \pm 0,14$ giờ. Có thể thấy, hoạt động khai thác chủ yếu diễn ra trong ngày bởi khu vực khai thác gần bờ với khoảng cách di chuyển ngắn. Khoảng thời gian này tương đối ngắn và phù hợp vì đảm bảo cho ốc Cà na còn sống và bán được giá cao. Số ngày được ngư dân khai thác trong một tháng trung bình $17,24 \pm 0,41$ ngày và khai thác trung bình $6,90 \pm 0,13$ tháng/năm (Bảng 3 ). Số ngày khai thác và số tháng khai thác của người dân phụ thuộc chủ yếu vào chế độ thủy triều hay con nước và mùa vụ xuất hiện ốc Cà na trong năm tại vùng biển ven bờ tỉnh Trà Vinh.

Bảng 3. Thời gian khai thác ốc Cà na khu vục vùng biển ven bờ tỉnh Trà Vinh $(C \tilde{a}$ mẫu = 42)

\begin{tabular}{lr}
\hline Nội dung & TB \pm SE (Min-Max) \\
\hline Thời gian ngâm bẫy (giờ) & $9,68 \pm 0,26(6,00-12,00)$ \\
Thời gian một chuyến thu và đặt bẫy (giờ) & $6,26 \pm 0,14(5,00-8,00)$ \\
Số ngày khai thác/tháng (ngày) & $17,24 \pm 0,41(14,00-25,00)$ \\
Số tháng khai thác/năm (tháng) & $6,90 \pm 0,13(6,00-9,00)$ \\
\hline
\end{tabular}

Kết quả khảo sát cho thấy, sản lượng 1 chuyến khai thác trung bình $56,55 \pm 2,79 \mathrm{~kg}$ /chuyến/tàu. Sản lượng khai thác trung bình 1 tháng khoảng $943,69 \pm 35,19 \mathrm{~kg} /$ tháng và sản lượng trung bình năm 6.432,74 $\pm 207,98$ kg/năm (Bảng 4). Sản lượng khai thác ốc Cà na tại vùng biển ven bờ tỉnh Trà Vinh cao hơn so với các đổi tượng động vật thân mềm khác tại các khu vực ven biển miền Trung Việt Nam như Khánh Hòa, Bình Định (Phan Đức Ngại và ctv., 2015, 2016a, 2016b).

\section{Bảng 4. Sản lượng khai thác ốc Cà na tại vùng biển ven bờ tỉnh Trà Vinh $(C \tilde{o}$ mẫu $=42)$}

\begin{tabular}{lr}
\hline Nội dung & TB \pm SE (Min-Max) \\
\hline Sản lượng 1 chuyến đặt bẫy (kg/chuyến/tàu) & $56,55 \pm 2,79(20,00-100,00)$ \\
Sản lượng trung bình tháng (kg/tháng) & $943,69 \pm 35,19(440,00-1.500,00)$ \\
Sản lượng trung bình năm (kg/năm) & $6.432,74 \pm 207,98(3.360,00-10.080,00$ \\
\hline
\end{tabular}

\subsubsection{Khía cạnh tài chính}

Kết quả khảo sát cho thấy, chi phí cố định đầu tư cho nghề khai thác ốc Cà na là $51,38 \pm 2,30$ triệu đồng. Trong đó, chi phí chủ yếu là bẫy lồng xếp chiếm $31,85 \pm 0,41 \%$ và vỏ tàu $33,08 \pm 0,49 \%$. Chi phí mua máy tàu chiếm $27,17 \pm 0,36 \%$, còn lại là các chi phí khác chiếm $6,90 \pm 0,20 \%$. Chi phí khấu hao tài sản cố định trung bình $0,010 \pm 0,001$ triệu đồng cho 1 chuyến đi biển (Bảng 5). Tương tự, nghiên cứu của Long et al. (2018) và Nguyễn Thanh Long và ctv. (2018) cho thấy chi phí cố định nghề khai thác ốc Cà na thấp hơn so với các ngành nghề khai thác khác ở vùng ĐBSCL. Trong đó, chi phí vỏ tàu và ngư cụ chiếm phần lớn trong chi phí cố định (Long et al., 2018; Nguyễn Thanh Long, 2015, 2016, 2017; Nguyễn Thanh Long và ctv., 2018). 
Bảng 5. Chi phí cố định nghề khai thác ốc Cà na vùng biển ven bờ tỉnh Trà Vinh $(C \tilde{o}$ mẫu = 42)

\begin{tabular}{lrrr}
\hline \multirow{2}{*}{ Nội dung } & \multicolumn{2}{c}{ Chi phí cố định } & $\begin{array}{c}\text { Chi phí khấu khao (triệu } \\
\text { dồng/chuyến) }\end{array}$ \\
\cline { 2 - 4 } & TB \pm SE (Min-Max) & Tỷ lệ (\%) & TB \pm SE (Min-Max) \\
\hline Vỏ tàu (triệu đồng) & $17,02 \pm 0,82(8,00-30,00)$ & $33,08 \pm 0,49$ & $0,006 \pm 0,000(0,001-0,013)$ \\
Máy tàu (triệu đồng) & $13,88 \pm 0,58(7,00-20,00)$ & $27,17 \pm 0,36$ & $0,005 \pm 0,000(0,001-0,010)$ \\
Bâyy lồng (triệu đồng) & $16,96 \pm 0,84(6,00-30,00)$ & $31,85 \pm 0,41$ & $0,006 \pm 0,000(0,001-0,013)$ \\
Chi phí khác (triệu đồng) & $3,51 \pm 0,17(2,00-6,00)$ & $6,90 \pm 0,20$ & $0,001 \pm 0,000(0,000-0,003)$ \\
Tổng chi phí cố định (triệu đồng) & $51,38 \pm 2,30(24,00-86,00)$ & 100 & $0,010 \pm 0,001(0,002-0,020)$ \\
\hline
\end{tabular}

Chi phí biến đổi cho hoạt động khai thác ốc của 1 chuyến biển trung bình $1,32 \pm 0,03$ triệu đồng và một năm là $156,10 \pm 5,42$ triệu đồng. Trong đó, chi phí dành cho nhân công và chi phí dầu chiếm phần lớn lần lượt là $33,59 \pm 0,83 \%$ và $32,80 \pm 1,18 \%$. Còn lại là các chi phí nhớt, mồi bẫy, lương thực và một số chi phí khác (Bảng 6). Cũng giống như nghiên cứu của Long et al. (2018) và Nguyễn Thanh Long và ctv. (2018) chi phí dành cho nhiên liệu (dầu) và chi phí nhân công.

Bảng 6. Chi phí biến đổi nghề khai thác ốc Cà na vùng biển ven bờ tỉnh Trà Vinh $(C \tilde{o}$ mẫu $=42)$

\begin{tabular}{|c|c|c|c|}
\hline \multirow{2}{*}{ Nội dung } & \multicolumn{2}{|c|}{$\begin{array}{c}\text { Chi phí biến đổi/chuyến biển (triệu } \\
\text { đồng) }\end{array}$} & \multirow{2}{*}{$\begin{array}{c}\begin{array}{c}\text { Chi phí biến đổi/năm (triệu } \\
\text { đồng) }\end{array} \\
\text { TB } \pm \text { SE (Min-Max) }\end{array}$} \\
\hline & TB \pm SE (Min-Max) & Tỷ lệ (\%) & \\
\hline$\overline{\text { Dầu }}$ & $0,43 \pm 0,02(0,25-0,70)$ & $32,80 \pm 1,18$ & $49,77 \pm 1,60(29,40-72,00)$ \\
\hline Nhớt & $0,06 \pm 0,01(0,02-0$ & & \\
\hline Mồi bẫy & & & $6,86 \pm 0,95$ \\
\hline Lương thực & & & $13,12 \pm 0,61$ \\
\hline Nhân công & $\pm 0,02(0,20-0,80)$ & $33,59 \pm 0$ & $53,10 \pm 2,65(25,20-100,80)$ \\
\hline Chi phí khác & $\pm 0,11(0,10-0,40)$ & $0,74 \pm 0,05$ & $26,55 \pm 1,32(12,60-50,40)$ \\
\hline Tồn chinhí hiến đổi & $1,32 \pm 0,03(0,84-1,83)$ & 100 & $156,10 \pm 5,42(94,92-243,08$ \\
\hline $\begin{array}{l}\text { Tổng chi phí cho } 1 \\
\text { thác ốc Cà na trung } \\
\text { trong đó chi phí khẩu } \\
\text { yếu là chi phí biến đổ } \\
\text { khai thác } 1,87 \pm 0,10 \\
\text { bình } 0,53 \pm 0,10 \text { triệu } \\
\text { nghề khai thác ốc Cà n }\end{array}$ & $\begin{array}{l}\text { Ến đi biển của nghề khai } \\
, 33 \pm 0,03 \text { triệu đồng, } \\
\text { hiếm tỷ lệ thấp còn chủ } \\
\text { nh thu cho } 1 \text { chuyến đi } \\
\text { ồng với lợi nhuận trung } \\
\text { Tỷ suất lợi nhuận của } \\
\text { hu vực biền ven bờ tỉnh }\end{array}$ & \multicolumn{2}{|c|}{$\begin{array}{l}\text { Trà Vinh là } 0,40 \pm 0,07 \text { lần. Tỷ suất lợi nhuận của } \\
\text { nghề khai thác ốc Cà na vùng biển ven bờ tỉnh trà } \\
\text { Vinh cao hờn so với nghề lưới kéo nhưng thấp hơn } \\
\text { so với nghề lưới rê, lưới đáy và rập xếp tại các khu } \\
\text { vực của vùng ĐBSCL. Kết quả cho thẩy mặc dù tỷ } \\
\text { suất lợi nhuận của nghề này không cao nhưng đã góp } \\
\text { phần tạo thu nhập và công ăn việc làm ồn định sinh } \\
\text { kế của người dân địa phương. }\end{array}$} \\
\hline
\end{tabular}

Bảng 7. Hiệu quả tài chính nghề khai thác ốc Cà na vùng biển ven bờ tỉnh Trà Vinh $(C \tilde{o}$ mẫu $=42)$

\begin{tabular}{lrr}
\hline \multirow{2}{*}{ Nội dung } & Chuyến biển & Cả năm \\
\cline { 2 - 3 } & TB \pm SE (Min-Max) & TB \pm SE (Min - Max) \\
\hline Tổng chi phí (triệu đồng) & $1,33 \pm 0,03(0,85-1,83)$ & $157,23 \pm 5,44(95,80-234,65)$ \\
Tồng chi phí khấu hao (triệu đồng) & $0,01 \pm 0,00(0,00-0,02)$ & $1,05 \pm 0,05(0,48-2,24)$ \\
Tổng chi phí biến đổi (triệu đồng) & $1,32 \pm 0,03(0,84-1,83)$ & $156,10 \pm 5,42(94,92-243,08)$ \\
Tổng doanh thu (triệu đồng) & $1,87 \pm 0,10(0,70-3,50)$ & $228,405 \pm 8,15(122,50-315,00)$ \\
Tổng lợi nhuận (triệu đồng) & $0,53 \pm 0,10(-0,63-1,92)$ & $51,11 \pm 10,74(-100,88-172,43)$ \\
Tỷ suât lợi nhuận (lần) & $0,40 \pm 0,07(-0,45-1,21)$ & $0,40 \pm 0,07(-0,45-1,21)$ \\
\hline
\end{tabular}

3.1.3. Khó khăn, thuận lợi và tiềm năng khai thác

Kết quả khảo sát cho thấy, nghề khai thác ốc Cà na vùng biển ven bờ tỉnh Trà Vinh có thuận lợi chủ yếu là kỹ thuật khai thác đơn giản với khu vực khai thác gần khu vực sinh sống. Bên cạnh đó, sản phẩm được tiêu thụ dễ dàng, tận dụng được nguồn lao động sẵn có, nguồn lợi ốc Cà na trong khu vực nhiều và lợi nhuận cao cũng được người dân cho là những thuận lợi khi tham gia nghề này (Bảng 8).

Thời tiết không ổn định và việc bị mất ngư cụ khai thác như lồng bẫy là những khó khăn chủ yếu mà ngư dân khai thác gặp phải. Bên cạnh đó, việc gia tăng số lượng tàu khai thác trong vùng cùng với 
sản phẩm bị thương lái ép giá và một phần thiếu nhân công là một trong những yếu tố tác động bất lợi đến nghề khai thác ốc ở vùng biển ven bờ tỉnh Trà Vinh (Bảng 8).

Bảng 8. Những thuận lợi và khó khăn nghề khai thác ốc Cà na biển ven bờ tỉnh Trà Vinh $(C \tilde{o}$ mẫu = 42)

\begin{tabular}{lcclcc}
\hline Thuận lợi & $\begin{array}{c}\text { Số mẫu } \\
\text { (Số hộ) }\end{array}$ & $\begin{array}{c}\text { Xếp } \\
\text { hạng }\end{array}$ & Khó khăn & $\begin{array}{c}\text { Số mẫu } \\
\text { (Số hộ) }\end{array}$ & Xếp hạng \\
\hline Kỹ thuật khai thác đơn giản & 34 & 1 & Thời tiết không ổn định & 37 & 1 \\
Khu vực khai thác gần & 25 & 2 & Mất lồng bẫy & 26 & 2 \\
Sản phẩm dễ tiêu thụ & 18 & 3 & Số tàu khai thác tăng & 16 & 3 \\
Lao động sẵn có & 13 & 4 & Thương lái ép giá & 9 & 4 \\
Sản lượng nhiều & 11 & 5 & Thiếu lao động & 7 & 5 \\
Lợi nhuận cao & 5 & 6 & - & - & - \\
\hline
\end{tabular}

\subsection{Nguồn lợi ốc Cà na khu vực biển ven bờ tỉnh Trà Vinh}

Kết quả điều tra sản lượng ốc Cà na đánh bắt ở

khu vực biển ven bờ tỉnh Trà Vinh trong khoảng thời gian từ ngày 12/05 đến ngày 19/09/2019 được thể hiện ở Bảng 9.

Bảng 9. Dũ liệu sản lượng - cường lực khai thác quần thể ốc Cà na biển ven bờ Trà Vinh từ ngày 12/05/2019 đến ngày 19/09/2019

\begin{tabular}{rlrrrrr}
\hline Tuần & Thời gian & $\begin{array}{r}\text { Sản lượng } \\
\text { khai thác } \\
(\mathbf{k g}), \mathbf{c i}\end{array}$ & $\begin{array}{r}\text { Cường lực khai } \\
\text { thác (lần/ngày), } \\
\mathbf{f i}\end{array}$ & $\begin{array}{r}\text { Năng suất } \\
\text { khai thác } \\
\text { ci/fi=Yi }\end{array}$ & $\begin{array}{r}\text { Sản lượng } \\
\text { khai thác } \\
\text { tích lúy, Ki }\end{array}$ & $\begin{array}{r}\text { Cường lực } \\
\text { khai thác } \\
\text { tích lúy, Fi }\end{array}$ \\
\hline 1 & $12-18 / 5 / 2019$ & $7.371,9$ & 102 & 72,27 & 0 & 0 \\
2 & $19-25 / 5 / 2019$ & $5.991,8$ & 95 & 63,07 & $7.371,9$ & 102 \\
3 & $26 / 5-1 / 6 / 2019$ & $2.242,2$ & 48 & 46,71 & $13.363,7$ & 197 \\
4 & $2-8 / 6 / 2019$ & $4.107,0$ & 69 & 59,52 & $15.605,9$ & 245 \\
5 & $9-15 / 6 / 2019$ & $4.516,3$ & 78 & 57,90 & $19.712,9$ & 314 \\
6 & $16-22 / 6 / 2019$ & $3.003,1$ & 71 & 42,30 & $24.229,2$ & 392 \\
7 & $23-29 / 6 / 2019$ & $2.923,0$ & 64 & 45,67 & $27.232,3$ & 463 \\
8 & $30 / 6-6 / 7 / 2019$ & $2.780,8$ & 47 & 59,17 & $30.155,3$ & 527 \\
9 & $7-13 / 7 / 2019$ & $2.608,9$ & 59 & 44,22 & $32.936,1$ & 574 \\
10 & $14-20 / 7 / 2019$ & $1.991,9$ & 53 & 37,58 & $35.545,0$ & 633 \\
11 & $21-27 / 7 / 2019$ & $2.355,9$ & 67 & 35,16 & $37.536,9$ & 686 \\
12 & $28 / 7-3 / 8 / 2019$ & $1.166,7$ & 32 & 36,46 & $39.892,8$ & 753 \\
13 & $4-10 / 8 / 2019$ & $1.166,1$ & 40 & 29,15 & $41.059,5$ & 785 \\
14 & $11-17 / 8 / 2019$ & $2.444,5$ & 53 & 46,12 & $42.225,6$ & 825 \\
15 & $18-24 / 8 / 2019$ & $2.251,1$ & 55 & 40,93 & $44.670,1$ & 878 \\
16 & $25-31 / 8 / 2019$ & $1.317,3$ & 46 & 28,64 & $46.921,2$ & 933 \\
17 & $1-7 / 9 / 2019$ & $1.247,6$ & 42 & 29,70 & $48.238,5$ & 979 \\
18 & $8-14 / 9 / 2019$ & $2.136,8$ & 66 & 32,38 & $49.486,1$ & 1.021 \\
19 & $15-21 / 9 / 2019$ & 208,2 & 17 & 12,25 & $51.622,9$ & 1.087 \\
\hline
\end{tabular}

Áp dụng mô hình của Leslie and Davis (1939) cho thấy kích thước quần thể ốc Cà na khu vực biển ven bờ tỉnh Trà Vinh có kích thước ước tính là $82.842,39 \pm 7.424,77 \mathrm{~kg}$ (95\% CI: 67.868,31 $99.152,8 \mathrm{~kg}$ ) với hệ số khả năng khai thác $9,89 * 10^{-4}$ $\pm 1,74 * 10^{-4}$ (95\% CI: $6,22 * 10^{-4}-13,57 * 10^{-4}$ ).
Tuy nhiên, do hệ số khả năng khai thác hay đánh bắt $(0,0008)$ nhỏ hơn 0,02 hay $2 \%$ trữ lượng của quần thể bị đánh bắt nên kích thước quần thể ốc Cà na được ước tính dựa trên mô hình của DeLury (1947) (Hình 3). 


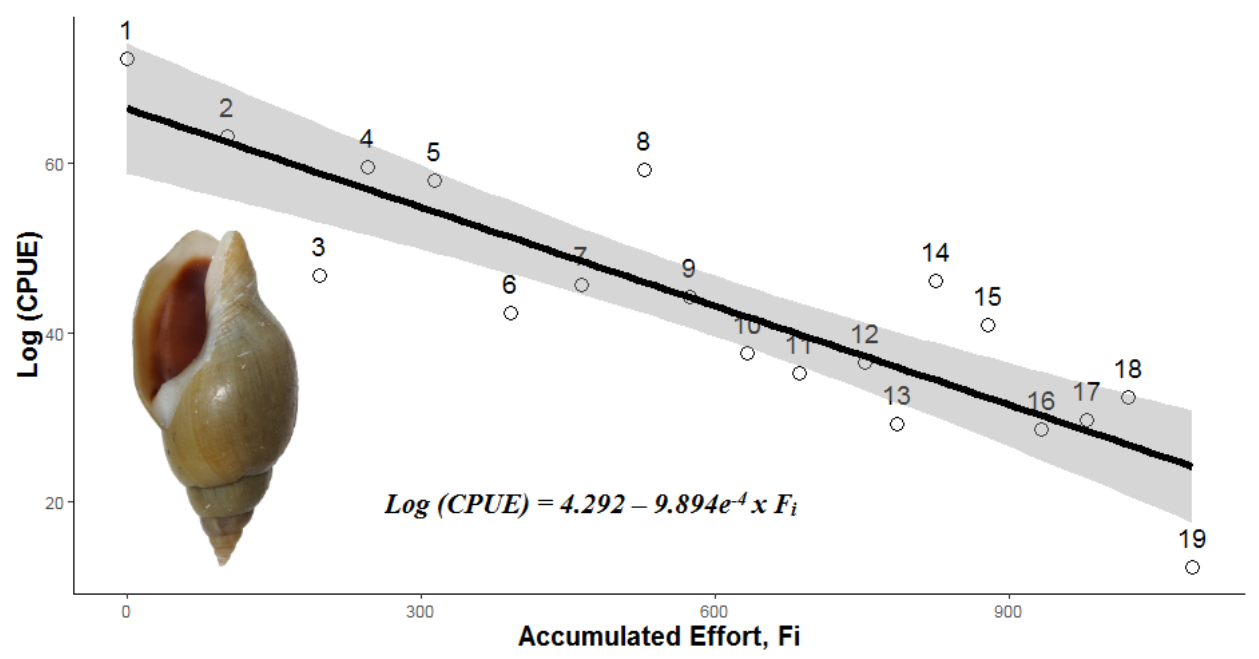

Hình 3. Kích thước quần thể ốc Cà na vùng biển ven bờ Trà Vinh dựa trên mô hình DeLury (1947)

Kết quả tính toán kích thước quần thể ốc dựa trên mô hình DeLury (1947) cho thấy kích thước quần thể ốc Cà na khu vực biển ven bờ tỉnh Trà Vinh là $73.904 \pm 6.684 \mathrm{~kg}(95 \% \mathrm{CI}: 59.802,88.006 \mathrm{~kg})$ với hệ số hiệu quả đánh bắt $9,894 * 10^{-4}(95 \% \mathrm{CI}$ : $\left.6,218 * 10^{-4}, 13,570^{*} 10^{-4}\right)$.

Khu vực ven biển tỉnh Trà Vinh ghi nhận 42 loài chân bụng hay ốc với 17 loài có giá trị kinh tế được khai thác ngoài tự nhiên (Nguyễn Văn Tú, 2019). Phần lớn các loài có giá trị kinh tế được khai thác ở quy mô nhỏ lẻ chỉ có ốc Cà Na với sản lượng nhiều được ngư dân khai thác với quy mô như một nghề khai thác. Kết quả tính toán kích thước quần thể ốc Cà na khu vực ven biển tỉnh Trà Vinh đại diện cho các cá thể ốc Cà na khai thác có kích thước lớn hơn $1 \mathrm{~cm}$ mắt lưới của bẫy lồng.

\section{KẾT LUẬN VÀ ĐỀ XUẤT}

\subsection{Kết luận}

Khai thác ốc Cà na là một nghề mới ở khu vực biển ven bờ tỉnh Trà Vinh từ năm 2011 và có mùa vụ khai thác từ tháng 3 đến tháng 10 âm lịch. Phương tiện khai thác ốc có công suất và trọng tải phù hợp cho đánh bắt ở vùng biển ven bờ. Mặc dù tỷ suất lợi nhuận không cao so với các nghề khai thác ven biển khác nhưng nghề khai thác ốc Cà na đã đóng góp tạo công ăn việc làm và ổn định sinh kế của ngư dân ven biển tỉnh Trà Vinh. Nguồn lợi ốc Cà na vùng ven biển tỉnh Trà Vinh ước tính từ 59.802 đến $88.006 \mathrm{~kg}$ và hệ số khả năng khai thác từ $6,218 * 10^{-4}$ đến $13,570 * 10^{-4}$.

\section{2. Đề xuất}

Nghiên cứu đánh giá nguồn lợi sử dụng các phương pháp khác như phương pháp thay đổi tỉ lệ (Change-in-Ratio method), phương pháp chỉ số loại bỏ (Index-Removal method) ốc Cà na khu vực biển ven bờ tỉnh Trà Vinh vào những năm tiếp theo để đánh giá chính xác về kích thước quần thể từ đó đưa ra các chính sách quản lý, khai thác, hợp lý và bền vững nguồn tài nguyên này.

Nghiên cứu đặc điểm sinh học và sinh thái học đối với ốc Cà na để làm cơ sở cho các nghiên cứu tiếp theo.

\section{LỜI CẢM ONN}

Nghiên cứu này thực hiện được nhờ sự hỗ trợ kinh phí từ đề tài cấp tỉnh Trà Vinh: "Nghiên cứu cơ sở khoa học sinh thái để phát triển nông nghiệp bền vững thị xã Duyên Hải, tỉnh Trà Vinh" mã số nhiệm vụ: 118/KQNC-SKHCN. Nhóm tác giả xin cảm ơn các hộ dân khai thác ốc Cà na khu vực ven biển tỉnh Trà Vinh đã cung cấp các thông tin để hoàn thiện nghiên cứu này.

\section{TÀI LIỆU THAM KHẢO}

Bùi Quang Nghị (2011). Ghi nhận thành phần loài động vật thân mềm (Mollusca) từ chuyến khảo sát Biển Đông năm 2007. Hội nghị Khoa hoc toàn quốc về Sinh thái và Tài nguyên sinh vật lần thư IV (trang 771-778). Nhà xuất bản Nông nghiệp.

Chinh, N. (1999). Checklist of marine molluscs of economic value in Vietnam. In J. Hylleberg (Eds.) Proceedings of the Ninth Workshop of the Tropical Marine Mollusc Programme (pp. 181- 
182). Phuket Marine Biological Center Special Publication.

Cochrane, K. L. (Ed.). (2002). A fishery manager's guidebook. Management measures and their application. FAO Fisheries Technical Paper, No. 424.

DeLury, D. B. (1947). On the estimation of biological populations. Biometrics, 3(4), 145-167.

Derek, H. O. (2016). Introductory Fisheries analyses With R. CRC Press Taylor \& Francis Group.

Đặng Ngọc Thanh (Chủ biên). (2003). Biển Đông: Sinh vật và Sinh thái biển (tập IV). Nhà xuất bản Đại học Quốc gia Hà Nội.

Đỗ Văn Tứ, Takenori Sasaki \& Lê Hùng Anh, (2019). Nhũng loài ốc (Mollusca: Gastropoda) phổ biến ở ven biển, ven đảo Việt Nam. Nhà xuất bản Khoa học tự nhiên và Công nghệ.

Food and Agriculture Organization of the United Nation. (2018). The State of World Fisheries and Aquaculture 2018 - Meeting the sustainable development goals. Rome, Licence: CC BY-NCSA 3.0 IGO.

Fischler, K. J. (1965). The use of catch-effort, catch sampling, and tagging data to estimate a population of blue crabs. Transactions of the American Fisheries Society, 94(4), 287310. https://doi.org/10.1577/15488659(1965)94[287:TUOCCA]2.0.CO;2

Hoàng Văn Huân (2018). Xây dụng bản đồ (Atlas) hiện trạng và dụ báo thủy động lực vùng biển và bò̀ biển (tù $0-30 m$ nuoớc) tỉnh Trà Vinh đến 2050 (Báo cáo kết quả nghiên cứu đề tài cấp Tỉnh). Viện Kỹ thuật biển.

Hylleberg, J. \& Kilburn, R. N. (2003). Marine molluscs of Vietnam. Annotations, Voucher, Material, and Species in Need of Verification. Phuket Marine Biological Center Special Publication.

Krebs, C. J. (1999). Ecological Methodology $\left(2^{\text {nd }}\right.$ ed.). Addison-Welsey Educational Publishing.

Leslie, P. H. \& Davis, D. H. S. (1939). An attempt to determine the absolute number of rats on a given area. Journal of Animal Ecology, 8(1), 94-113.

Long, N. T., Van, M. V., Phuong, D. T., Tojo, N. \& Dinh, T. D. (2018). Satus of major coastal fishing activities in the Mekong Delta, Vietnam. International Journal of Scientific and Research Publication, 8(9), 415-421.

MolluscaBase (Eds.). (2020). MolluscaBase. Tomlinia frausseni Thach, 2014. Accessed at: http://www.molluscabase.org/aphia.php?p=taxde tails\&id=754850 on 2020-03-02.

Nguyễn Quang Hùng, Đỗ Anh Duy, Lưu Xuân Hòa \& Hoàng Đình Chiều. (2016). Đa dạng sinh hoc và nguồn lợi thủy sản trong hệ sinh thái rùng ngập mặn Việt Nam. Nhà xuất bản Nông Nghiệp.

Nguyễn Thanh Long. (2015). Nghiên cứu nghề lưới rập xếp ở tỉnh Cà Mau. Tạp chí Khoa học Truò̀ng Đại hoc Cần Tho', 41b, 94-100.

Nguyễn Thanh Long. (2016). Nghiên cứu hoạt động khai thác của nghề lưới kéo đơn ven bờ và xa bờ ở tỉnh Bạc Liêu. Tạp chí Khoa hoc Truờng Đại hoc Cần Tho, 45b, 112-118.

Nguyễn Thanh Long. (2017). Nghiên cứu hoạt động khai thác của nghề lưới rê hỗn hợp ở tỉnh Trà Vinh. Tạp chí Khoa hoc Truờng Đại học Cần Tho, 49b, 109-115.

Nguyễn Thanh Long, Huỳnh Văn Hiền, Mai Viết Văn, Trần Đắc Định \& Naoki Tojo. (2018). Đánh giá hoạt động khai thác thủy sản ở Đồng bằng Sông Cửu Long. Tạp chí Khoa học Truờng Đại học Cần Tho; 54(7b), 102-109.

Nguyễn Văn Thuận \& Trần Đức Phú. (2015). Nghiên cứu lựa chọn kết cấu lồng bẫy khai thác ghẹ tại vùng biển Việt Nam. Tạp chí Khoa hoc và Công nghệ Thủy sản, 2, 144-149.

Nguyễn Văn Tú (2019). Nghiên cúu cơ sở khoa hoc sinh thái để phát triển nông nghiệp bền vũng thị xã Duyên Hải, tỉnh Trà Vinh (Báo cáo kết quả nghiên cứu cấp Tỉnh). Viện Sinh học nhiệt đới.

Oanh, T. T. K., Lap, N. V., Lan, N. T. M., Thong, T. D. \& Quyen, V. T. H. (2018). Natural and environmental characteristics of Tra Vinh coastal area, Mekong Delta Vietnam for the development of hard clam culture. Journal of Biodiversity and Environmental Sciences, 13(2), 58-67.

Phan Đức Ngại, Võ Sĩ Tuấn, Nguyễn Văn Long, Hứa Thái Tuyến \& Phan Thị Kim Hồng. (2015). Đặc trưng nguồn lợi sinh vật đáy đầm Đề $\mathrm{Gi}$, tỉnh Bình Định. Tạp chí Khoa hoc và Công nghệ Biển, 15(4), 382-391.

Phan Đức Ngại, Võ Sĩ Tuấn, Nguyễn Văn Long \& Hứa Thái Tuyến. (2016a). Đặc trưng và biến động nguồn lợi sinh vật đáy thủy vực Nha Phu, tỉnh Khánh Hòa. Tạp chí Khoa hoc và Công nghẹ Biển, 16(3), 328-335.

Phan Đức Ngại, Võ Sĩ Tuấn, Nguyễn Văn Long, Hứa Thái Tuyến \& Nguyễn An Khang. (2016b). Đặc trưng nguồn lợi sinh vật đáy các vùng nước đầm miền Trung. Tạp chí Khoa hoc và Công nghệ Biển, 16(1), 80-88.

Thach, N. N. (2014). A new Tomlinia (Gastropoda: Buccinidae) from Vietnam. Gloria Maris, 53(1), 1-5.

Thach, N. N. (2016a). New records of Molluscs from Vietnam. 48HrBooks company.

Thach, N. N. (2016b). Vietnamese new mollusks: Seashells, Landsnails, Cephalopods: with 59 new species. Akron. Ohio 48HrBooks company. 
Thach, N. N. (2017). New shells of Southeast Asia: Seashells \& Land snail: with 2 new genera and 85 new species. $48 \mathrm{HrBooks}$ company.

GBIF Secretariat. (2020). GBIF Backbone

Taxonomy - Checklist dataset. Retrieved March 2, 2020, from https://doi.org/10.15468/39omei.

Trần Đức Phú, Nguyễn Trọng Lương, Nguyễn Văn Thuận \& Nguyễn Y Vang. (2012). Hiệu quả khai thác thủy sản của nghề lồng bẫy cải tiến tại Ninh Thuận. Tạp chí Khoa hoc và Công nghệ Thủy sản, 2, 59-64.
Trương Sĩ Kỳ, Đỗ Hữu Hoàng \& Hứa Thái Tuyến. (1996). Đặc điểm sinh sản của sò huyết (Anadara granosa) sống ở vùng ven biển Trà Vinh. Tuyển tập nghiên cúu Biển, 7, 103-112.

UBND tỉnh Trà Vinh. (2013). Quyết định Ban hành Quy định về quản lý một số lĩnh vực trong hoạt động thủy sản trên địa bàn tỉnh Trà Vinh (Số 12/2013/QĐ-UBND).

http://vbpl.vn/travinh/Pages/vbpqtoanvan.aspx ?ItemID=75583\&Keyword= 